\title{
Dynamics of the double burden of malnutrition and the changing nutrition reality
}

\author{
Barry M Popkin, Camila Corvalan, Laurence M Grummer-Strawn
}

The double burden of malnutrition (DBM), defined as the simultaneous manifestation of both undernutrition and overweight and obesity, affects most low-income and middle-income countries (LMICs). This Series paper describes the dynamics of the DBM in LMICs and how it differs by socioeconomic level. This Series paper shows that the DBM has increased in the poorest LMICs, mainly due to overweight and obesity increases. Indonesia is the largest country with a severe DBM, but many other Asian and sub-Saharan African countries also face this problem. We also discuss that overweight increases are mainly due to very rapid changes in the food system, particularly the availability of cheap ultra-processed food and beverages in LMICs, and major reductions in physical activity at work, transportation, home, and even leisure due to introductions of activity-saving technologies. Understanding that the lowest income LMICs face severe levels of the DBM and that the major direct cause is rapid increases in overweight allows identifying selected crucial drivers and possible options for addressing the DBM at all levels.

\section{Introduction}

The global health community has been slow to acknowledge the challenge of the large proportion of lowincome and middle-income countries (LMICs) facing the double burden of malnutrition (DBM), which is the coexistence of undernutrition (ie, micronutrient deficiencies, underweight, and childhood stunting and wasting) and overweight, obesity, and diet-related noncommunicable diseases. $2 \cdot 28$ billion $^{1}$ or more children and adults worldwide are estimated to be overweight and more than 150 million children are stunted. ${ }^{2,3}$

Several studies describe the double burden of nutritional deficiencies ( childhood s tunting or w asting, a nd micronutrient deficiencies) a nd o verweight a nd o besity affecting c ountries, h ouseholds, a ndi ndividuals. Included are the first studies that measured the DBM at the household level, ${ }^{4-6}$ now this is represented by growing literature that has focused on understanding the dimensions of the problem, causes, consequences, and possible solutions. ${ }^{7-13}$ The analysis has pinpointed several reasons for this health crisis, many related to the stage of the nutrition transition dominated by reduced physical activity and increased access to less healthy, highly processed foods and beverages. ${ }^{1421}$ However, how to translate this evidence into effective actions is unclear.

Building on the 2013 Lancet Series on maternal and child undernutrition ${ }^{22}$ and complementing other major scientific initiatives such as the EAT-Lancet Commission on healthy diets from sustainable food systems $\mathrm{s}^{23}$ and the Lancet Commission on the global syndemic of obesity, undernutrition, and climate change, ${ }^{24}$ this Series highlights the new nutrition reality: that there are multiple forms of malnutrition that overlap in different ways and in different places. ${ }^{13}$ Additionally, addressing all forms of malnutrition will require new ways of designing, targeting, and implementing programmes and policies to accelerate progress in improving nutrition globally.
We also want to acknowledge that the effect of undernutrition over the past four to five decades will affect our health for many future years. Although stunting has declined greatly from the early 1990s, the stunting from the past three to four decades will subsequently have a great effect decades later on increases in visceral fat and greater risks of major noncommunicable diseases as discussed by Wells and colleagues, ${ }^{25}$ in the second paper in this Series, ${ }^{26}$ and in the key cohort studies..$^{27-29}$

This 2019 Series is timely, with the recent UN Decade of Action on Nutrition and the Sustainable Development Goals shifting focus from predominantly undernutrition, or single sides of malnutrition, to all forms of malnutrition. ${ }^{30,31}$ Further, major UN and other international institutions and donors are revisiting their strategies to reconsider the scope of nutrition priorities, developing strategy documents, and formulating initiatives to focus on overweight and obesity as well as undernutrition. ${ }^{32}$

The papers in this Series take this concern for malnutrition in all forms a step further and focus on not only the epidemiology and larger societal changes in the food system and other major demographic and economic dimensions, but also the biological underpinnings of stunting and subsequent adiposity and the risk of noncommunicable disease. ${ }^{25}$

The papers in this Series also take the issue of the DBM into the programme and policy area ${ }^{33}$ by building on the work of double-duty interventions, ${ }^{11}$ which focus on reducing both undernutrition and overweight and obesity. This Series also shows how ignoring obesity in programmes focused on preventing malnutrition at various ages has affected obesity and the $\mathrm{DBM}^{33}$ and focuses on the economic effects of health programmes and policies. ${ }^{34}$ This Series paper introduces the epidemiology of the DBM, presents changes in global estimates of the DBM and its components, and uses
Lancet 2020; 395: 65-74 Published Online December 15, 2019 https://doi.org/10.1016/ S0140-6736(19)32497-3

This is the first in a Series of four papers about the double burden of malnutrition See Editorial page 2

Department of Nutrition and Carolina Population Center, University of North Carolina at Chapel Hill, Chapel Hill, NC, USA (Prof B M Popkin); Institute of Nutrition and Food Technology (INTA), University of Chile, Santiago, Chile (C Corvalan PhD); and Department of Nutrition for Health and Development, World Health Organization, Geneva, Switzerland (L M Grummer-Strawn PhD) Correspondence to: Prof Barry M Popkin, Carolina Population Center, University of North Carolina, Chapel Hill, NC 27516, USA

popkin@unc.edu 


\section{Key messages}

- In low-income and middle-income countries (LMICs), stunting and wasting, and thinness in women are declining while overweight is increasing in most age groups. According to the most recent surveys, a severe double burden of malnutrition (DBM) is defined as wasting in more than $15 \%$ and stunting in more than $30 \%$ of children aged $0-4$ years, thinness in women (body-mass index $<18.5 \mathrm{mg} / \mathrm{kg}^{2}$ ) in more than $20 \%$ of females aged $15-49$ years, and adult or child overweight, was found in 48 countries using the $20 \%$ overweight prevalence threshold, 35 countries using the $30 \%$ overweight prevalence threshold, and ten countries using the $40 \%$ overweight prevalence threshold of all LMICs.

- Severe levels of the DBM have shifted to the countries in the poorest income quartile. Although, in the 1990s, the DBM was typically seen in the highest income bracket countries among the LMICs, today the DBM predominates in poorest LMICs that have much lower gross domestic product per capita, particularly in south and east Asia and sub-Saharan Africa.

- Increases in overweight are the result of changes in the global food system that make less nutritious food cheaper and more accessible, as well as to the decrease in physical activity due to major technological shifts in the workplace, home, and transportation. In south Asian and sub-Saharan African countries, the risk of overweight and obesity is greater among the higher-wealth households and urban areas, and in many other LMICs the risk of the DBM is starting to concentrate among people with low incomes and in rural areas.

- LMICs face a new nutrition reality. The shifts in the global food system are accelerating increases in overweight. Concurrently these same shifts have changed the diet of children aged 0-4 years but the effect on stunting needs further research. LMICs need to implement interventions to improve diet quality to address undernutrition and overnutrition across the lifecycle.

repeated household surveys to explore aspects of the DBM. We then provide an overview of the nutrition and food system transitions that explain the large increase in the DBM, particularly among the lowest-income LMICs. The final section of this Series paper discusses the consequences of the problem and possible solutions. .,8,12,35-37 $^{-3}$

\section{The DBM and its prevalence: country and household epidemiology}

In this paper and the subsequent papers in this Series we use the word malnutrition to refer to both wasting, stunting, and thinness, and overweight and obesity. Although micronutrient malnutrition is recognised as a component of undernutrition, we have not been able to include this form of malnutrition in our DBM estimates, because of insufficient data.

\section{Country-level DBM}

The DBM at the country level is defined as having a high prevalence of both undernutrition and overweight and obesity in at least one population group. We examined which LMICs had a DBM (ie, a prevalence of wasting of $>15 \%$, stunting of $>30 \%$, and thinness in women of $>20 \%$, and an adult or child overweight prevalence of $>20 \%,>30 \%$, or $>40 \%$ ). The cutoffs for undernutrition are defined as follows: a weight-forheight $\mathrm{Z}$ score of less than -2 for wasting; a height-forage $\mathrm{Z}$ score of less than -2 for children aged $0-4$ years for stunting; and a body-mass index (BMI) of less than $18 \cdot 5 \mathrm{~kg} / \mathrm{m}^{2}$ for thinness in adult women. For overweight, the cutoffs are a BMI Z score of greater than 2 in children younger than 18 years, and a BMI of greater than $25 \mathrm{~kg} / \mathrm{m}^{2}$ in more than $20 \%, 30 \%$, or $40 \%$ of the adult (older than 18 years) population ${ }^{35}$ (figure 1 ; appendix pp 6-11). We use a combination of overweight and obesity because extensive epidemiological research associates BMI of $25 \mathrm{~kg} / \mathrm{m}^{2}$ or higher (or possibly an even lower threshold) with the risks of noncommunicable diseases across LMICs. ${ }^{36-42}$

Of the 123 LMICs with data from the 1990s, the number of countries facing the DBM was $45(37 \%)$ based on a $20 \%$ overweight prevalence cutoff, 22 (18\%) based on a $30 \%$ cutoff, and 15 (12\%) based on a $40 \%$ cutoff (figure 1A; appendix pp 6-8). Of the 126 LMICs with data from the 2010 s, the number of countries facing the DBM was $48(38 \%)$ based on a $20 \%$ overweight prevalence cut off, $35(28 \%)$ based on a $30 \%$ cutoff, and ten ( $8 \%$ ) based on a $40 \%$ cutoff (figure 1B; appendix pp 9-11).

The DBM is especially prevalent in sub-Saharan Africa, south Asia, and east Asia and the Pacific. In countries with data for both time periods, increases and decreases were roughly balanced, using the $30 \%$ and $40 \%$ cutoffs. Increases in the DBM were observed particularly in Asia, whereas improvements were observed in Latin America and the Caribbean, and the Middle East and north Africa.

\section{Economic development and the DBM at the national level}

Examining the changes in the DBM status by quartile of gross domestic products (GDP) per capita in 1990, we can see that increases in the number of countries with a DBM from the 1990s to the 2010s are within the lowest income quartile, whereas the number of countries with a DBM has declined in the top three income quartiles (figure 2). The largest increases in number of the DBM countries were observed using the $20 \%$ and $30 \%$ adult overweight prevalence cutoffs.

This highlights the driving role of overweight in shaping countries now facing a high DBM, with the greatest effect among the countries in the lowest quartile of GDP per capita. Figure 3 further highlights these changes in the DBM by income quartile. At the same time, the total number of countries with a severe DBM (ie, defined using the $40 \%$ overweight cutoff) declined, related mainly to substantial declines in wasting and stunting.

\section{Household-level DBM}

The DBM at the household level was defined as one or more individuals with wasting, stunting, or thinness and one or more individuals with overweight or obesity within the same household. The DBM can occur in one of four ways: a child is both stunted and overweight; the mother is overweight and one of her children younger than 5 years has wasting the mother is overweight and one of her children younger than 5 years is stunted; or the mother is thin and one of her children is 
A Countries with DBM in the 1990 s according to weight and height data

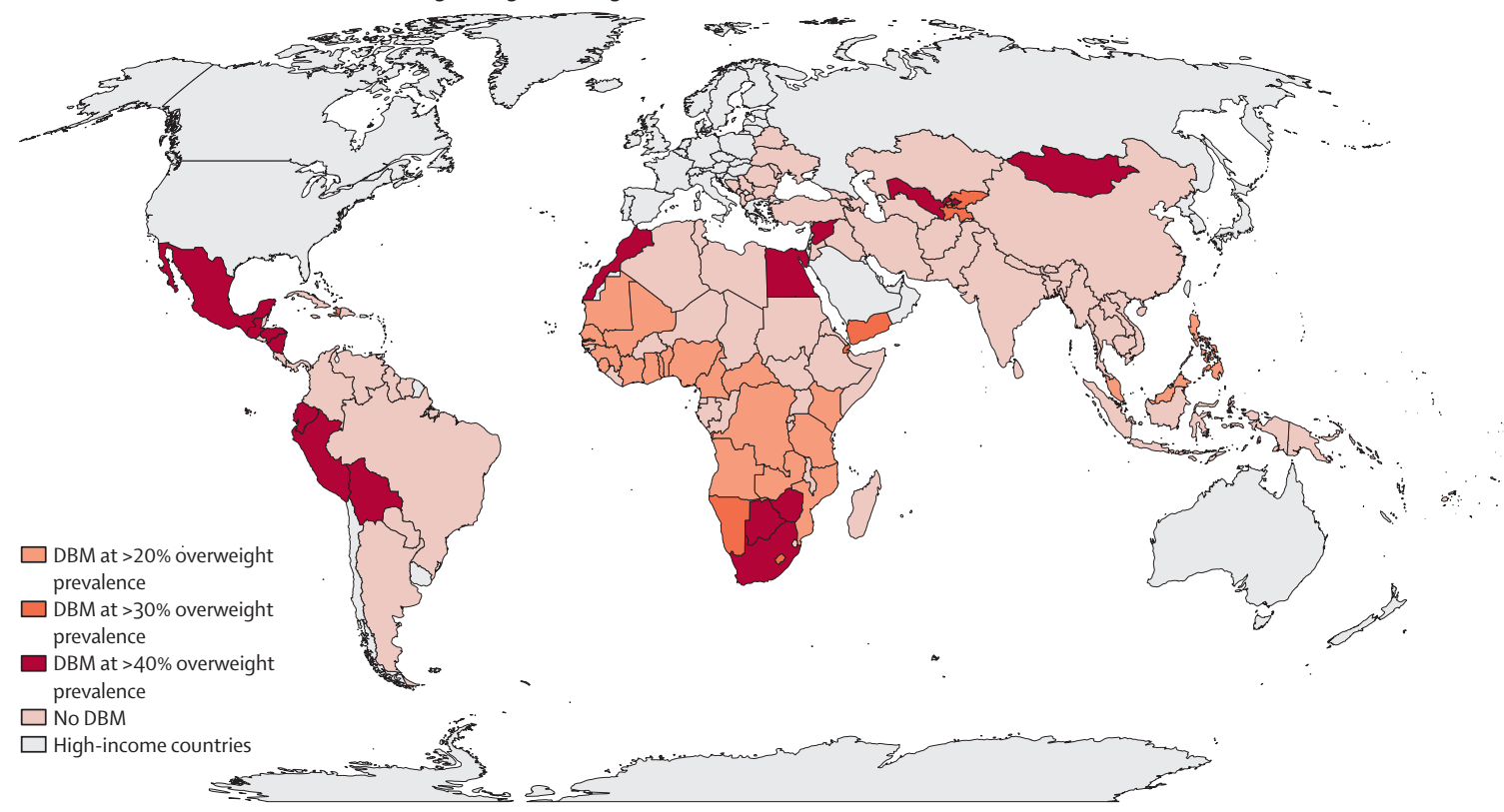

B Countries with DBM in the 2010 s according to weight and height data

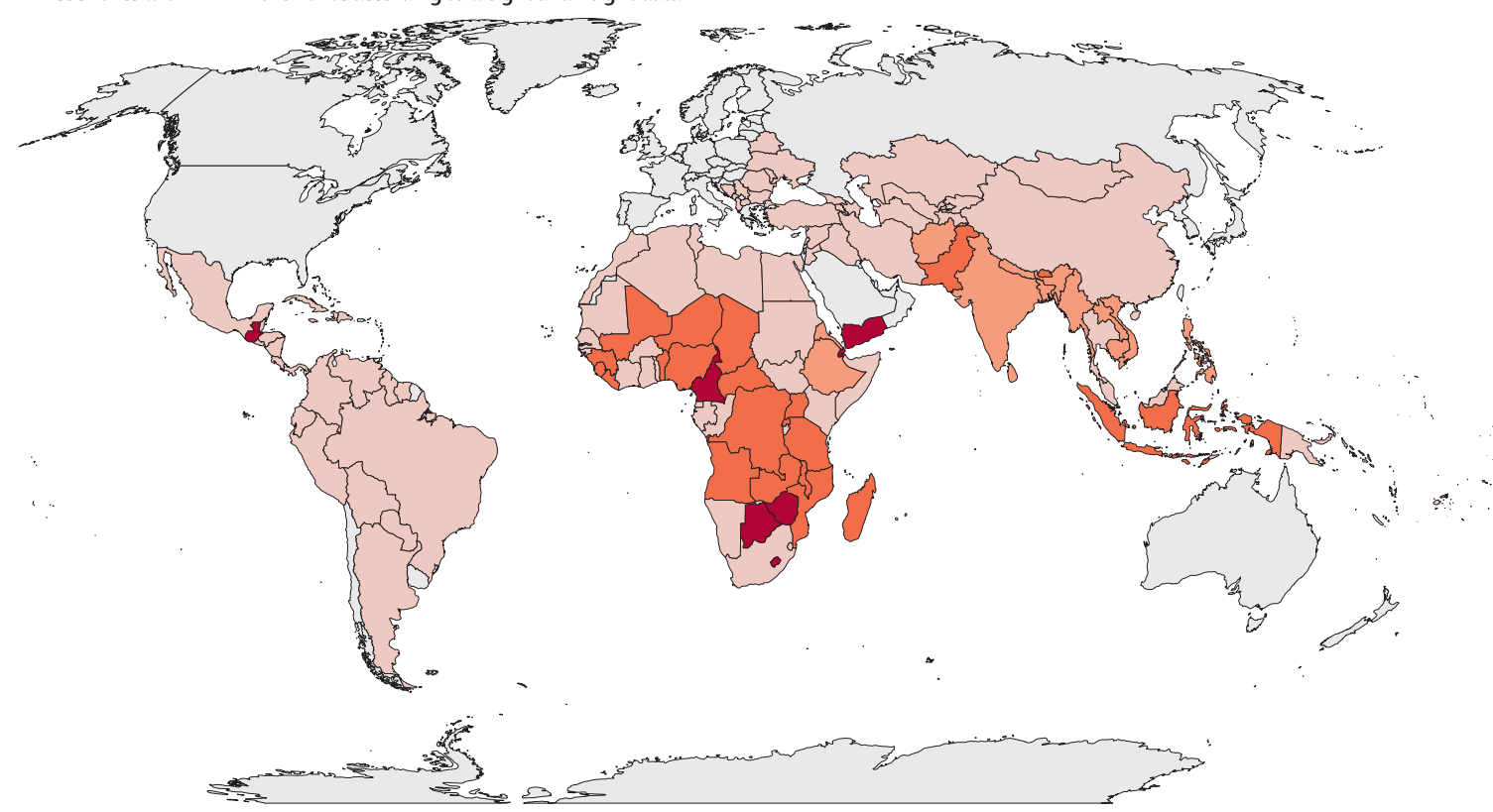

Figure 1: The global DBM in low-income and middle-income countries based on weight and height data from the 1990s (A) and 2010s (B)

DBM at the country level was defined as a high prevalence of both undernutrition (wasting and stunting in children aged 0-4 years, and thinness in adult women) and overweight and obesity (defined according to three different overweight prevalence thresholds: $20 \%$, 30\%, and 40\%) in at least one population group. Data sources are UNICEF, WHO, World Bank, and NCD-RisC estimates, supplemented with selected Demographic and Health Surveys and other country direct measures. $\mathrm{DBM}=$ double burden of malnutrition.

overweight. Appendix pp 14-15 shows the prevalence of each of these scenarios and the total prevalence of household DBM.

Household-level DBM is driven primarily by the combination of women with overweight and children with stunting (highest prevalence of all four possible combinations in every country with the highest level of change where increases in the prevalence of the DBM are occurring). By contrast, the contribution of the fourth category of the DBM (mother with thinness and child with overweight) is extremely small, with less than $1 \%$ prevalence in most countries.
For more on the Demographic and Health Surveys see https://dhsprogram.com/ 

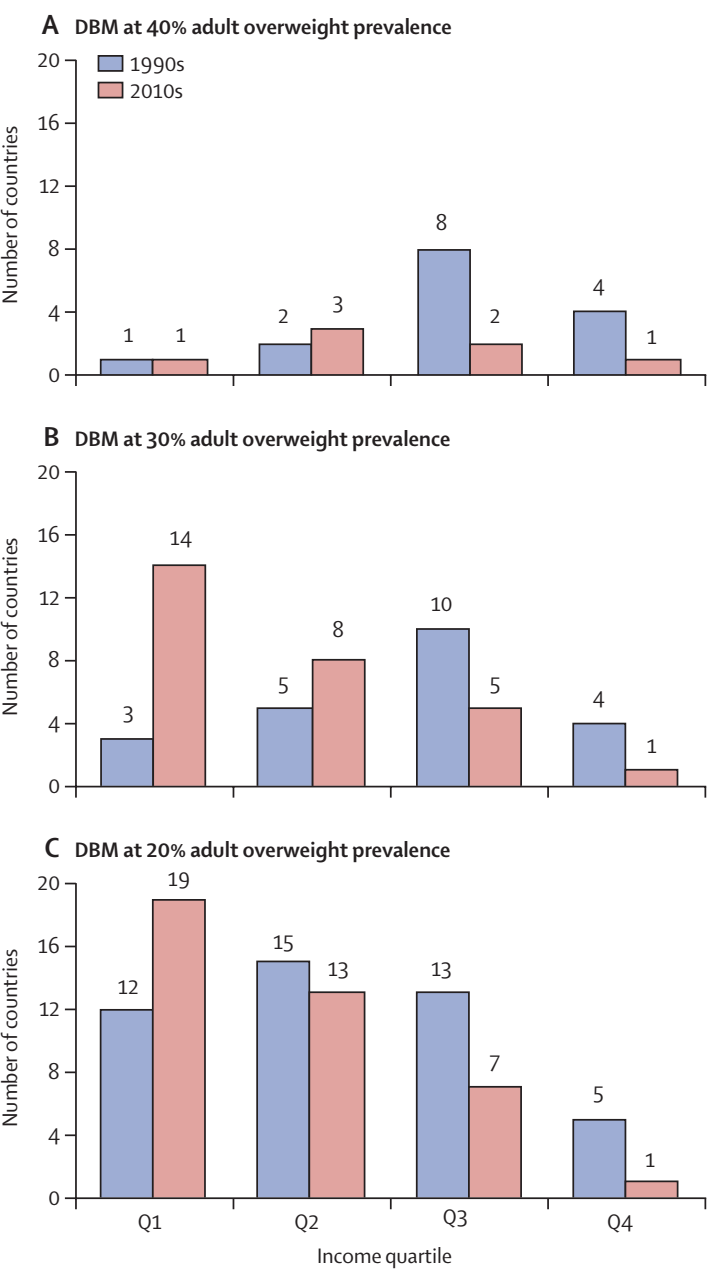

Figure 2: Countries with a high DBM in the 1990s and 2010s, by overweight prevalence threshold and income quartile DBM at the country level was defined as a high prevalence of both undernutrition (wasting and stunting in children aged 0-4 years, and thinness in adult women) and overweight and obesity, defined according to three different overweight prevalence thresholds: $20 \%$ (A), 30\% (B), and 40\% (C), in at least one population group. Countries were only included here if they had DBM data available for both time periods (1990s and 2010s). Q1 is lowest wealth and Q4 is highest wealth according to gross domestic product per capita (purchasing power parity). Data sources are UNICEF, WHO, World Bank, and NCD-RisC estimates, supplemented with selected Demographic and Health Surveys and other country direct measures for the 1990s. DBM=double burden of malnutrition. $\mathrm{Q}=$ quartile.

The prevalence of total household-level DBM ranges from less than $3 \%$ to nearly $35 \%$, with over a quarter of households experiencing a DBM in Azerbaijan, Guatemala, Egypt, Comoros, and São Tomé and Príncipe. The total household-level DBM is shown in appendix p 22 for 22 countries with at least two surveys of more than 15 years apart. Comparing the earliest and the latest surveys in these countries, five countries showed reductions in their DBM and 15 (including India, China, and Indonesia) showed increases (appendix p 22).
Economic development and the DBM at the household level In appendix pp 12-15, the GDP per capita and householdlevel DBM relationship is similar in the two time periods examined (1990s and 2010s), with the highest levels of household DBM seen in the middle of the income range (figure 4). However, the entire curve has shifted slightly upward (about 2-3 additional percentage points) in the most recent time period at all income levels.

\section{Individual-level DBM}

The second paper in this Series ${ }^{26}$ addresses the underlying developmental origins biology that can lead to a child having both stunting and overweight. The prevalence of individual-level DBM for children aged $0-4$ years is shown in the appendix (pp 14-15, 22). The proportion of children who have both stunting and overweight ranges from less than 1\% in Myanmar, Colombia, and Nepal to more than 15\% in Albania. Among the 20 countries with earliest-to-latest-year data spanning 15 or more years, about half showed that the DBM was declining in children at the individual level and half showed that it was increasing (appendix p 22).

\section{Changes in malnutrition over time: equity considerations}

Nearly all countries saw declines in child wasting or stunting, with a third declining by more than one percentage point per year (appendix pp 16-17). Conversely, nearly all countries saw an increase in overweight among women, with over a third of countries increasing by more than one percentage point per year (appendix pp 18-19).

From a public health perspective, where this overweight is emerging and whether the burden is now, or in the future, and greater among people living in poverty is important to know. To provide some sensitivity to where increased overweight is occurring, we looked at the prevalence and annualised changes in prevalence in all countries with 2 years of anthropometric data and examined the differences in the changes in the prevalence of overweight and obesity between the poorest and the highest-wealth quintiles in the earliest and most recent survey periods (figure 5).

A positive annualised difference indicates that people in the poorest quintile face a greater prevalence of overweight and obesity than do those in higher wealth quintiles and suggests increasing disparities between the lowest and the highest wealth quintiles (see appendix p 19 for the data and appendix pp 1-5 for the methodology). We show a growing prevalence of overweight and obesity among lower-wealth households in most countries in Latin America and the Caribbean, eastern Europe and central Asia, and east Asia (led by China and Indonesia). By contrast, sub-Saharan Africa and south Asia have the largest increases in prevalence of overweight and obesity among higher-wealth households (appendix p 19). We cannot predict with existent data whether these regions will see a shift toward greater 
overweight among lower-wealth households in the future. A study shows that in all LMICs other than south Asia and sub-Saharan Africa, rural overweight and obesity is growing faster than in urban areas and highlights the need for shared solutions targeted to both urban and rural areas. ${ }^{43}$

The next section explores the global food systems linked with a new nutrition reality now affecting even the poorest LMICs.

\section{Transitions that explain the current shifts in the DBM towards lower-income countries}

We found that of the countries that have a new DBM at any overweight or obesity prevalence threshold, the largest proportion were in the lower quartiles GDP per capita purchasing power parity (figure 3 ). At the same time, the number of countries in the upper income quartiles with a DBM decreased. This result reflects increasing overweight among lower-income countries that have not reduced stunting, wasting, or thinness below the WHO-UNICEF cutoff levels. We focus the following discussion on the changing food system and new nutrition reality that these poorest LMICs are facing.

Economic change certainly has been crucial to the reductions in wasting, stunting, and thinness as well as declines in physical activity and major shifts in the food system that have resulted in an increase in consumption of ultra-processed foods. 16,20,21,44 49 In longitudinal studies in China, the increases in overweight were fuelled by a massive reduction in physical activity and most probably also in energy expenditure derived from the introduction of modern technology in market economic work, home production (eg, rice cookers, refrigerators, stoves), and transportation systems. . $^{18-21,48,50}$

However, very rapid changes in the diets and the food systems of most LMICs are where most of the recent change in energy imbalance that causes weight gain is focused. Offsetting t he e ffects of an y ul tra-processed food is difficult-eg, by drinking a $355 \mathrm{~mL}$ bottle of sugar-sweetened beverage, the consumer would be required to undertake a 1.5 mile walk or run for at least 15 min. ${ }^{39}$ Thus, we discuss later on mainly the shifts in the food system and diet changes over time. We conceptualise the food system as the entire process from production to the consumer..$^{51-53}$

This system includes the activities, infrastructure, and people involved in feeding the global population. Over the past several decades the relative influence and power among the various actors who affect and direct food production has increased, as has the penetration of modern food retailing and marketing throughout most LMICs. In this Series paper we touch on these dramatic changes only briefly. A more in-depth discussion of these changes can be found elsewhere ${ }^{16}$ and in more detail for Latin America and the Caribbean. ${ }^{53}$ These food system changes are clearly important for weight gain and overweight status but the literature on how these changes

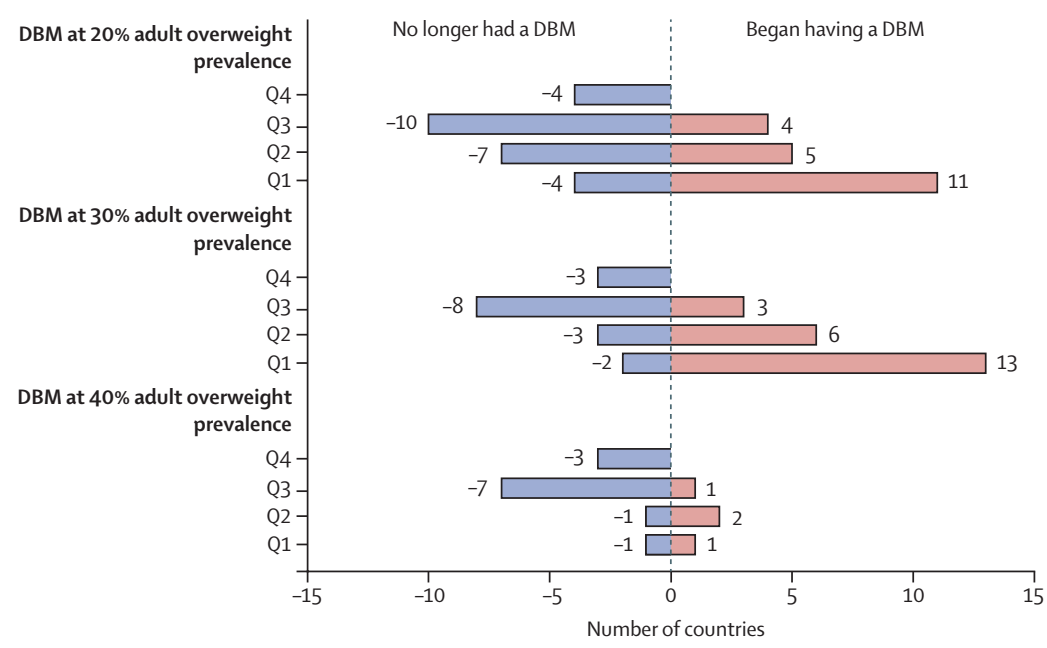

Figure 3: Number of countries that changed DBM status from the 1990 s to 2010 s, by gross income quartile DBM at the country level was defined as a high prevalence of both undernutrition (wasting and stunting in children aged 0-4 years, and thinness in adult women) and overweight and obesity (defined according to three different overweight prevalence thresholds: $20 \%, 30 \%$, and $40 \%$ ), in at least one population group. Countries were only included here if they had DBM data available for both time periods (1990s and 2010s). Q1 is lowest wealth and Q4 is highest wealth according to gross domestic product per capita (purchasing power parity). Data sources are UNICEF, WHO, World Bank, and NCD-RisC estimates, supplemented with selected Demographic and Health Surveys and other country direct measures for the $1990 \mathrm{~s}$. DBM=double burden of malnutrition. $\mathrm{Q}=$ quartile.

affect undernutrition is unclear and this association is understudied.

The general concept of the nutrition transition is that in each region of the world (not only countries but subregions within countries), a transformation in the way people eat, drink, and move at work, at home, in transport, and in leisure has affected the distribution of body composition and created nutritional problems. . $^{54,55}$

The transition has produced remarkable shifts in physical activity and diets in LMICs and a rapid increase in overweight, obesity, and nutrition-related non-communicable diseases..$^{20,21,48,50}$ As we have noted we only have suggestive information on ways that this transition affects infant diets for those facing a high risk of stunting and wasting. ${ }^{45,4749,56}$ In the past decade, no studies have been done on the exact causes of country-level or even household-level DBM. But we will describe briefly a new nutrition reality that is rapidly becoming the major driver of overweight and obesity among lower-income countries and also has unclear but increasing effects on undernutrition.

\section{The new nutrition reality}

The new nutrition reality is particularly important to acknowledge, because diet is an important driver of the DBM. ${ }^{57,58}$ Although we understand that changes in the past several decades in food marketing, access, and purchase of packaged processed foods have demarcated a new nutrition reality across the globe, this Series paper focuses on the effect on all LMICs while attempting to 


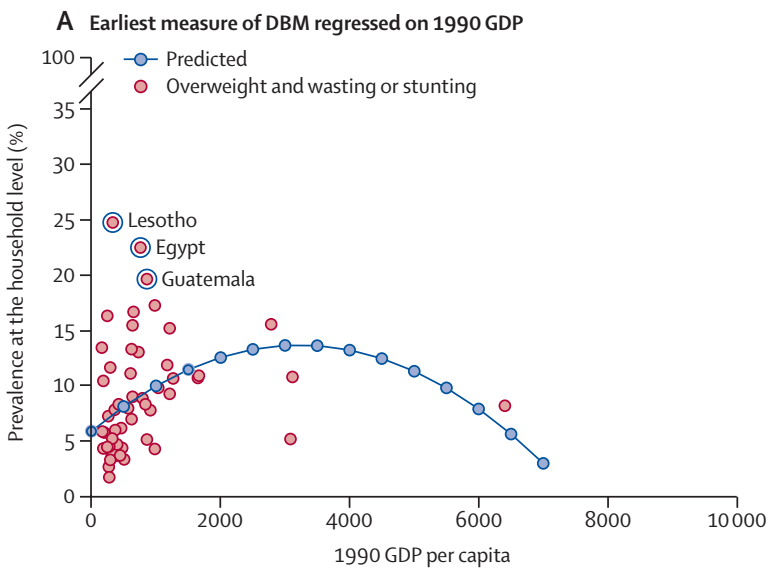

B Most recent measure of DBM regressed on $2010 \mathrm{GDP}$

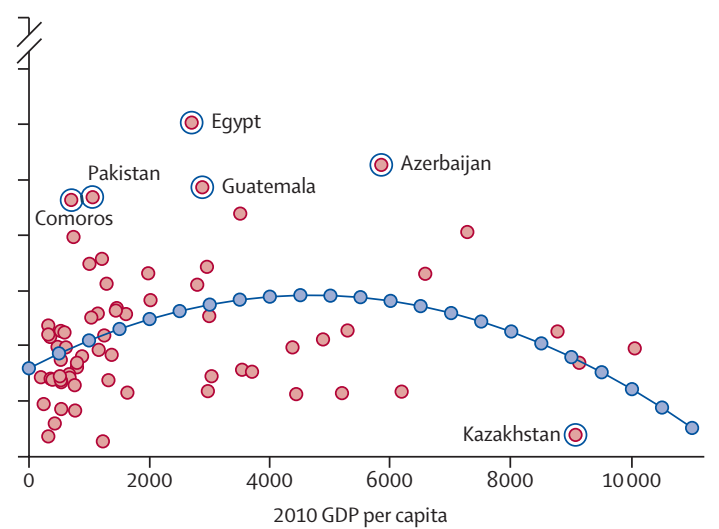

Figure 4: The association between GDP per capita (purchasing power parity) and regressions relating GDP per capita to prevalence of household-level DBM $\mathrm{DBM}$ at the household level was defined as one or more individuals with wasting, stunting, or thinness and one or more individuals with overweight or obesity within the same household. Data sources are the Demographic and Health Surveys with the exceptions of China (China Health and Nutrition Survey), Indonesia (Indonesian Family Life Survey), Mexico (Mexico National Survey of Health and Nutrition), Brazil (Brazil National Health Survey), and Vietnam (Vietnam Living Standards Survey). $\mathrm{DBM}=$ double burden of malnutrition. GDP=gross domestic product.

understand the effects on countries in different regions and with varying income levels. ${ }^{59-61}$ The growth in retail food $^{59,62,63}$ and the control of the entire food chain in many countries by agribusinesses, food retailers, food manufacturers, and food service companies have changed markedly. ${ }^{53,64}$ This change has been accompanied by the increased consumption of ultra-processed food purchases in LMICs. ${ }^{65,66}$ Ultra-processed, packaged foods rich in refined carbohydrates, fat, sugar, and salt are relatively inexpensive and often ready to eat. ${ }^{67}$

Evidence suggests these ultra-processed foods play a major role in increased obesity and non-communicable diseases. A randomised controlled trial done by a team at the US National Institutes of Health showed that adults with normal weight lost $0.9 \mathrm{~kg}$ in 2 weeks when fed a realfood diet and gained $0.9 \mathrm{~kg}$ when fed a diet composed of ultra-processed foods, following a cross-over design. ${ }^{14}$

Whether the hyperpalatability of ultra-processed food or the much higher energy density of these foods causes such a weight gain is unclear from this study. Additionally, two large European cohorts have shown a strong positive relation between ultra-processed foods and cardiovascular disease and all-cause mortality. ${ }^{68-70}$ The role of ultra-processed foods on stunting remains less clear, although, we would expect a negative effect if they are replacing nutrient-rich, energy-dense foods. ${ }^{14,69,70}$ Intake of ultra-processed foods during the first 1000 days of life is increasing and represents a newly emerging probable contributor of stunting, ${ }^{44-47,49,56,71,72}$ therefore perpetuating the DBM.

\section{The retail revolution}

The retail revolution, which has led to fresh markets increasingly disappearing and large and small food retailers replacing them, has swept the globe, as a series of studies by Reardon and others shows..$^{59,60,62-64,73}$ In Latin America and the Caribbean, sales of packaged processed food increased from about $10 \%$ of all food expenditures (both in-cash and in-kind sales) in 1990 to $60 \%$ in 2000 The bulk of this increase appears to be in ultra-processed unhealthy foods and beverages and the growth continues in this region. ${ }^{53,62,74}$ Similar increases in the penetration of modern food retailers emerged at different rates across Asia, Africa, and the Middle East. ${ }^{63}$

The Persian Gulf states ${ }^{63}$ have not been studied as carefully, although increased penetration of modern food retailers in this region presumably occurred even earlier than in other regions, because the area urbanised and had rapid growth in incomes. The changes vary across sub-Saharan Africa, north Africa, east Asia, southeast Asia, and south Asia but are accelerating in most countries in these regions. ${ }^{59,60,75}$ Urban areas were already dominated by a modern food retail sector in the mid-1990s, but most growth in the sub-Saharan African market has occurred in the 21st century. ${ }^{61}$

\section{Controlling the food supply}

The actors who control the food supply are changing. At the time of the green revolution and the growth of the global agricultural research sector between 1950 and 1969, countries, large agribusiness firms in the seed and fertiliser sector, and global foundations generated the change. ${ }^{51,53,6473,74,76}$ Although these players still have major roles in producing new technology, control of the food chain is transforming. Case studies from China Bangladesh, and India were the first to remark on this transformation ${ }^{64}$ and later research showed similar trends in Africa. ${ }^{60}$

These studies showed that the global and national public sectors were no longer the major influences of 
diets in LMICs. Rather, food retailers, food agribusinesses, global food companies, and the food service sector and their domestic local counterparts have contracts directly with farmers.

\section{Non-essential foods and beverages}

Sales of non-essential foods and beverages are growing rapidly. Sales volume data from Euromonitor International shows trends in increasing sales of non-essential or junk foods and sugar-sweetened beverages in Chile, South Africa, the Philippines, and Malaysia (appendix p 23). ${ }^{7}$ Appendix pp 20-21 present the sales data from Euromonitor International used to model the GDP relationship with both sales volumes and annualised changes in sales of sugar-sweetened beverages (appendix p 24) and junk foods (appendix p 25) in LMICs using data regressions. ${ }^{78}$

These results show that sales of sugar-sweetened beverages were already high in lower-income countries by 2017. The rapid growth of junk foods and sugarsweetened beverages in these countries exemplifies how aggressive this food sector is. India and China are two of the top five markets for sugary beverage manufacturers (appendix pp 26-27) and sugary beverages are expected to become these countries major markets in the next decade. The speed of change is particularly important in understanding how this nutrition reality is shifting.

\section{Key drivers of the new nutrition reality}

In LMICs, urbanisation, migration to cities, income growth, infrastructure improvements, and global trade policy liberalisation have spurred private investment in the food sector. ${ }^{54,61,74,7}$ The roles of income growth ${ }^{78}$ and other drivers associated with diet changes should not be downplayed. Equally important is how the increase in the number of women working outside the home ${ }^{53,79}$ and the value of their time in work have shaped the demand for food that is ready to eat or ready to heat. ${ }^{80}$ Monteiro calls this convenience in food preparation and consumption the ultra-processed food revolution..$^{65,66}$

Modern marketing and access to mass media have added to changes in conceptions of the ideal set of foods. Although power is shifting to large-scale food retailers, manufacturers, and food-service companies, ${ }^{53,64}$ the informal sector and smaller local companies remain understudied components of the food sector who are often important sources of food for low-income and rural populations.

\section{Conclusion}

This Series paper has shown that LMICs continue to have a high DBM; however, countries with a high DBM have lower incomes than the countries that had a high DBM in the early 1990s. The analysis of the dynamics of undernutrition and obesity suggest that the high DBM is being driven by the rapid increases in the prevalence of overweight and obesity occurring in these lower-income

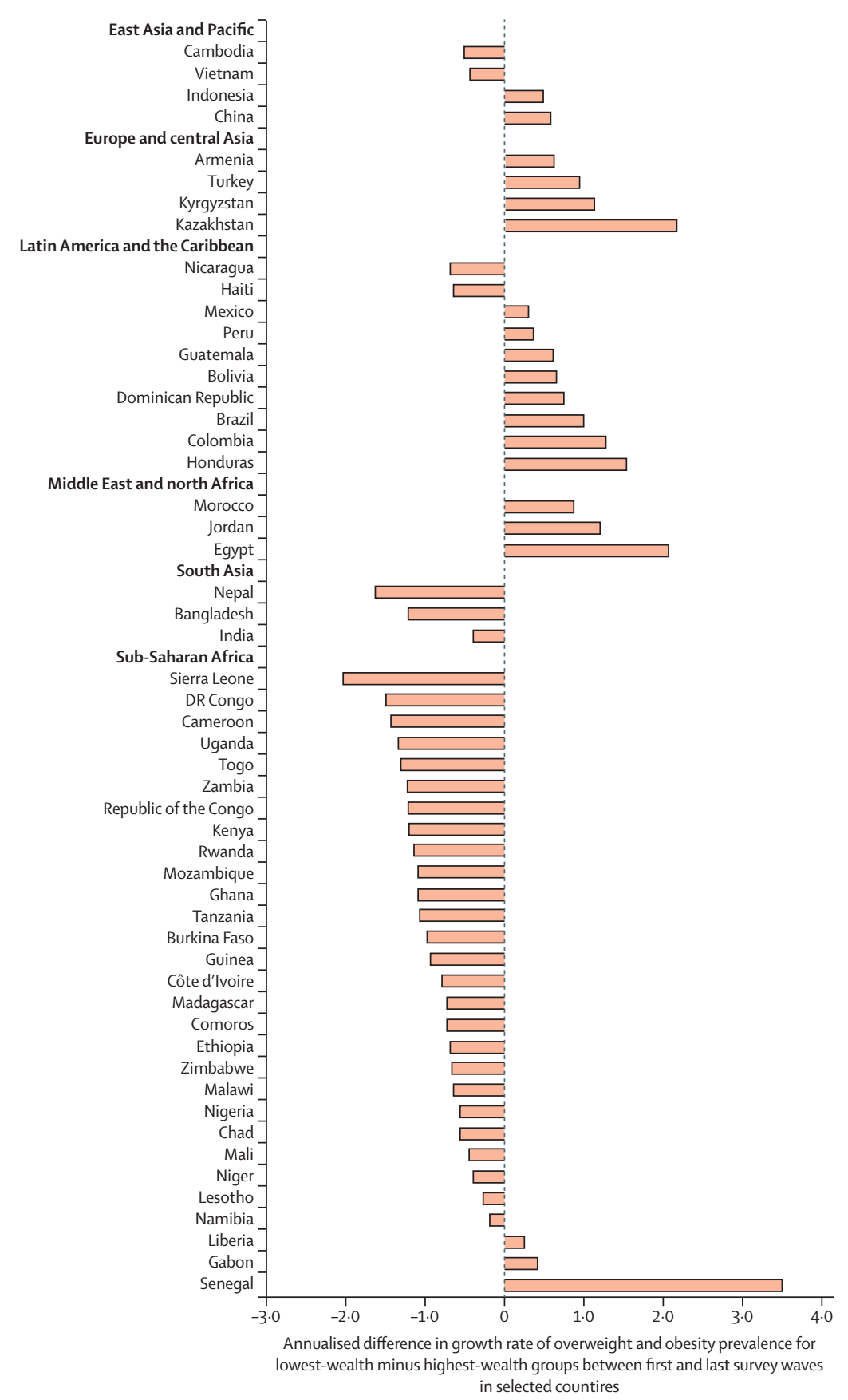

Figure 5: The shifting burden of overweight and obesity from higher-wealth to lower-wealth populations in sample countries

Positive difference indicates higher annualised growth in overweight and obesity prevalence for the lowest-wealth quartile. Countries presented here had earliest-to-latest-year data spanning 15 or more years, latest-year data after 2010, and a population greater than approximately 15 million (with the exception of Jordan and Kyrgyzstan, which both had smaller populations but were included for regional representation). The data presented are from years spanning 1988 to 2016, but exact years vary by country. The span of earliest-to-latest years collected ranges from 15 years to 24 years. All data are from the Demographic and Health Surveys with the exceptions of China (China Health and Nutrition Survey), Indonesia (Indonesian Family Life Survey), Mexico (Mexico National Survey of Health and Nutrition), Brazil (Brazil National Health Survey), and Vietnam (Vietnam Living Standards Survey). 
countries that are also experiencing a slower decline in the prevalence of undernutrition. A greater number of new countries with a high DBM were in the lowest GDP per capita (purchasing power parity) quartile of LMICs than in the 1990s. We show that this new nutrition reality is driven by important and rapid changes that have taken place in the food system. Conversion of the global and domestic retail food, food service, and agribusiness sectors of the economy, along with other transformations, ${ }^{52,53,60,64}$ have resulted in an important increased availability of ultra-processed foods in LMICs.

Ultra-processed food consumption has been linked to the risk of overweight and obesity, and non-communicable disease, and preliminary evidence shows that the consumption of these foods during the first 1000 day (pregnancy and infancy) early-life window could be also linked to stunting. Understanding and tackling the drivers of the food system shift, and enacting effective policies that address the challenges of the DBM, are urgently needed.

\section{Contributors}

BMP drafted the paper, tables, and figures. LMG-S and CC reviewed, suggested major revision of the structuring of the paper, and suggested additional analyses. All authors reviewed and edited the final revision.

\section{Declaration of interests}

We declare no competing interests.

\section{Acknowledgments}

Funding is from the National Institutes of Health (R01DK108148 and P2C HD050924). Funding for the preparation of the Series was provided by WHO, through a grant from the Bill \& Melinda Gates Foundation. The funder had no role in the analysis and interpretation of the evidence or in writing the paper and the decision to submit for publication. We thank Karen Ritter and Emily Busey for great programming, research, and graphics support, Frances Burton for administrative support, and Francesco Branco and the other authors of the Double Burden of Malnutrition Series for suggestions.

\section{References}

1 World Health Organization. Obesity and overweight factsheet. 2016 http://www.who.int/mediacentre/factsheets/fs311/en/ (accessed May 1, 2017).

2 International Food Policy Research Institute. 2017 global food policy report. Washington, DC: International Food Policy Research Institute (IFPRI), 2017

3 FAO, IFAD, UNICEF, WFP, WHO. The state of food security and nutrition in the world 2018: building climate resilience for food security and nutrition. 2018. https://www.who.int/nutrition/ publications/foodsecurity/state-food-security-nutrition-2018/en/ (accessed Nov 7, 2019).

4 Doak CM, Adair LS, Bentley M, Monteiro C, Popkin BM. The dual burden household and the nutrition transition paradox. Int $J$ Obes 2005; 29: 129-36.

5 Doak CM, Adair LS, Monteiro C, Popkin BM. Overweight and underweight coexist within households in Brazil, China and Russia. J Nutr 2000; 130: 2965-71.

6 Garrett JL, Ruel MT. Stunted child-overweight mother pairs: prevalence and association with economic development and urbanization. Food Nutr Bull 2005; 26: 209-21.

7 Victora CG, Rivera JA. Optimal child growth and the double burden of malnutrition: research and programmatic implications. Am J Clin Nutr 2014; 100: 1611S-12S.

8 Rivera JA, Pedraza LS, Martorell R, Gil A. Introduction to the double burden of undernutrition and excess weight in Latin America. Am J Clin Nutr 2014; 100: 1613S-16S.

9 Kroker-Lobos MF, Pedroza-Tobías A, Pedraza LS, Rivera JA. The double burden of undernutrition and excess body weight in Mexico. Am J Clin Nutr 2014; 100: 1652S-58S.
10 World Health Organization. Double-duty actions for nutrition: policy brief. 2017. https://www.who.int/nutrition/publications/ double-duty-actions-nutrition-policybrief/en/ (accessed Nov 7, 2019).

11 Hawkes C, Demaio AR, Branca F. Double-duty actions for ending malnutrition within a decade. Lancet Glob Health 2017; 5: e745-46.

12 Tzioumis E, Adair LS. Childhood dual burden of under- and overnutrition in low- and middle-income countries: a critical review. Food Nutr Bull 2014; 35: 230-43.

13 Global Nutrition Report independent expert group. 2018 global nutrition report: shining a light to spur action on nutrition. 2018. https://globalnutritionreport.org/reports/global-nutritionreport-2018/ (accessed Nov 7, 2019).

14 Hall KD, Ayuketah A, Brychta R, et al. Ultra-processed diets cause excess calorie intake and weight gain: A one-month inpatient randomized controlled trial of ad libitum food intake. Cell Matab 2019; 30: 1-10.

15 Popkin BM. Nutrition, agriculture and the global food system in low and middle income countries. Food Policy 2014; 47: 91-96.

16 Popkin BM. Relationship between shifts in food system dynamics and acceleration of the global nutrition transition. Nutr Rev 2017; 75: 73-82.

17 Popkin BM, Reardon T. Obesity and the food system transformation in Latin America. Obes Rev 2018; 19: 1028-64.

18 Monda KL, Adair LS, Zhai F, Popkin BM. Longitudinal relationships between occupational and domestic physical activity patterns and body weight in China. Eur J Clin Nutr 2008; 62: 1318-25.

19 Monda KL, Popkin BM. Cluster analysis methods help to clarify the activity-BMI relationship of Chinese youth. Obes Res 2005; 13: $1042-51$.

20 Ng SW, Norton EC, Guilkey DK, Popkin BM. Estimation of a dynamic model of weight. Empir Econ 2012; 42: 413-43.

21 Ng SW, Popkin BM. Time use and physical activity: a shift away from movement across the globe. Obes Rev 2012; 13: 659-80.

22 Horton R, Lo S. Nutrition: a quintessential sustainable development goal. Lancet 2013; 382: 371-72.

23 Willett W, Rockström J, Loken B, et al. Food in the Anthropocene: the EAT-Lancet Commission on healthy diets from sustainable food systems. Lancet 2019; 393: 447-92.

24 Swinburn BA, Kraak VI, Allender S, et al. The Global Syndemic of Obesity, Undernutrition, and Climate Change: The Lancet Commission report. Lancet 2019; 393: 791-846.

25 Wells JCK, Wibaek R, Poullas M. The dual burden of malnutrition increases the risk of cesarean delivery: evidence from India. Front Public Health 2018; 6: 292.

26 Wells JC, Sawaya AL, Wibeak R, et al. The double burden of malnutrition: aetiological pathways and consequences for health. Lancet 2019; published online Dec 15. https://doi.org/10.1016/ S0140-6736(19)32472-9.

27 Adair LS, Fall CH, Osmond C, et al. Associations of linear growth and relative weight gain during early life with adult health and human capital in countries of low and middle income: findings from five birth cohort studies. Lancet 2013; 382: 525-34.

28 Stein AD, Wang M, Martorell R, et al. Growth patterns in early childhood and final attained stature: data from five birth cohorts from low- and middle-income countries. Am J Hum Biol 2010; 22: 353-59.

29 Victora CG, Adair L, Fall C, et al. Maternal and child undernutrition: consequences for adult health and human capital. Lancet 2008; 371: 340-57.

30 WHO. United Nations decade of action. 2016. http://www.who.int/ nutrition/decade-of-action/en/ (accessed March 1, 2019).

31 Nilsson M, Griggs D, Visbeck M. Policy: map the interactions between Sustainable Development Goals. Nature 2016; 534: 320-22.

32 UN Children's Fund. Implementing taxes on sugar-sweetened beverages: an overview of current approaches and the potential benefits for children. 2019. https://scalingupnutrition.org/news/ implementing-taxes-on-sugar-sweetened-beverages-an-overview-ofcurrent-approaches/ (accessed March 19, 2019).

33 Hawkes C, Ruel MT, Salm L, Sinclair B, Branca F. Double-duty actions: seizing program and policy opportunities to address malnutrition in all its forms. Lancet 2019; published online Dec 15. https://doi.org/10.1016/S0140-6736(19)32506-1. 
34 Nugent R, Levin C, Hale J, Hutchison B. Economic effects of the double burden of malnutrition. Lancet 2019; published online Dec 15. https://doi.org/10.1016/S0140-6736(19)32473-0.

35 de Onis M, Borghi E, Arimond M, et al. Prevalence thresholds for wasting, overweight and stunting in children under 5 years. Public Health Nutr 2019; 22: 175-79.

36 Colin Bell A, Adair LS, Popkin BM. Ethnic differences in the association between body mass index and hypertension. Am J Epidemiol 2002; 155: 346-53.

37 Albrecht SS, Mayer-Davis E, Popkin BM. Secular and race/ethnic trends in glycemic outcomes by BMI in US adults: the role of waist circumference. Diabetes Metab Res Rev 2017; 33: e2889.

38 Expert Consultation WHO. Appropriate body-mass index for Asian populations and its implications for policy and intervention strategies. Lancet 2004; 363: 157-63.

39 Heyward VH, Gibson A. Advanced fitness assessment and exercise prescription 7th edition. Champaign Illinois: Human Kinetics Publishing, 2014

40 Misra A. Ethnic-specific criteria for classification of body mass index: a perspective for Asian Indians and American Diabetes Association position statement. Diabetes Technol Ther 2015; 17: 667-71.

41 Nair M, Prabhakaran D. Why do South Asians have high risk for CAD? Glob Heart 2012; 7: 307-14.

42 Joshi P, Islam S, Pais P, et al. Risk factors for early myocardial infarction in South Asians compared with individuals in other countries. JAMA 2007; 297: 286-94.

43 NCD Risk Factor Collaboration (NCD-RisC). Rising rural body-mass index is the main driver of the global obesity epidemic in adults. Nature 2019; 569: 260-64.

44 Pries AM, Huffman SL, Mengkheang K, et al. Pervasive promotion of breastmilk substitutes in Phnom Penh, Cambodia, and high usage by mothers for infant and young child feeding. Matern Child Nutr 2016; 12 (suppl 2): 38-51.

45 Pries AM, Huffman SL, Mengkheang K, et al. High use of commercial food products among infants and young children and promotions for these products in Cambodia. Matern Child Nutr 2016; 12 (suppl 2): 52-63.

46 Vitta BS, Benjamin M, Pries AM, Champeny M, Zehner E, Huffman SL. Infant and young child feeding practices among children under 2 years of age and maternal exposure to infant and young child feeding messages and promotions in Dar es Salaam, Tanzania. Matern Child Nutr 2016; 12 (suppl 2): 77-90.

47 Huffman SL, Piwoz EG, Vosti SA, Dewey KG. Babies, soft drinks and snacks: a concern in low- and middle-income countries? Matern Child Nutr 2014; 10: 562-74.

48 Bell AC, Ge K, Popkin BM. Weight gain and its predictors in Chinese adults. Int J Obes Relat Metab Disord 2001; 25: 1079-86.

49 Pries AM, Filteau S, Ferguson EL. Snack food and beverage consumption and young child nutrition in low- and middle-income countries: a systematic review. Matern Child Nutr 2019; 15 (suppl 4): e12729.

50 Bell AC, Ge K, Popkin BM. The road to obesity or the path to prevention: motorized transportation and obesity in China. Obes Res 2002; 10: $277-83$.

51 Anand SS, Hawkes C, de Souza RJ, et al. Food consumption and its impact on cardiovascular disease: importance of solutions focused on the globalized food system: a report from the workshop convened by the World Heart Federation. J Am Coll Cardiol 2015; 66: $1590-614$

52 Reardon T, Timmer CP. The economics of the food system revolution. Annu Rev Resour Econ 2012; 4: 225-64.

53 Popkin BM, Reardon T. Obesity and the food system transformation in Latin America. Obes Rev 2018; 19: 1028-64.

54 Popkin BM. The shift in stages of the nutrition transition in the developing world differs from past experiences! Public Health Nutr 2002; 5: 205-14.

55 Popkin BM, Adair LS, Ng SW. Global nutrition transition and the pandemic of obesity in developing countries. Nutr Rev 2012; 70: 3-21.

56 Pries AM, Huffman SL, Adhikary I, et al. High consumption of commercial food products among children less than 24 months of age and product promotion in Kathmandu Valley, Nepal. Matern Child Nutr 2016; 12 (suppl 2): 22-37.
57 Forouzanfar MH, Alexander L, Anderson HR, et al. Global, regional, and national comparative risk assessment of 79 behavioural, environmental and occupational, and metabolic risks or clusters of risks in 188 countries, 1990-2013: a systematic analysis for the Global Burden of Disease Study 2013. Lancet 2015; 386: 2287-323.

58 Black RE, Allen LH, Bhutta ZA, et al. Maternal and child undernutrition: global and regional exposures and health consequences. Lancet 2008; 371: 243-60.

59 Reardon T, Timmer CP, Minten B. Supermarket revolution in Asia and emerging development strategies to include small farmers. Proc Natl Acad Sci USA 2012; 109: 12332-37.

60 Reardon T, Tschirley D, Minten B, et al. Transformation of African agrifood systems in the new era of rapid urbanization and the emergence of a middle class. In: Badiane O, Makombe T, eds. Beyond a middle income Africa: transforming African economies for sustained growth with rising employment and incomes. Washington: International Food Policy Research Institute, 2015: 62-74.

61 Tschirley D, Reardon T, Dolislager M, Snyder J. The rise of a middle class in East and Southern Africa: Implications for food system transformation. J Int Dev 2015; 27: 628-46.

62 Reardon T, Berdegué JA. The rapid rise of supermarkets in Latin America: challenges and opportunities for development. Dev Policy Rev 2002; 20: 371-88.

63 Reardon T, Timmer CP, Barrett CB, Berdegue JA. The rise of supermarkets in Africa, Asia, and Latin America. Am J Agric Econ 2003; 85: 1140-46.

64 Reardon T, Chen KZ, Minten B, et al. The quiet revolution in Asia's rice value chains. Ann N Y Acad Sci 2014; 1331: 106-18.

65 Monteiro CA, Levy RB, Claro RM, de Castro IR, Cannon G. Increasing consumption of ultra-processed foods and likely impact on human health: evidence from Brazil. Public Health Nutr 2011; 14: 5-13.

66 Monteiro CA, Moubarac JC, Cannon G, Ng SW, Popkin B. Ultra-processed products are becoming dominant in the global food system. Obes Rev 2013; 14 (suppl 2): 21-28.

67 Poti JM, Mendez MA, Ng SW, Popkin BM. Is the degree of food processing and convenience linked with the nutritional quality of foods purchased by US households? Am J Clin Nutr 2015; 101: 1251-62.

68 Lawrence MA, Baker PI. Ultra-processed food and adverse health outcomes. BMJ 2019; 365: 12289.

69 Rico-Campà A, Martínez-González MA, Alvarez-Alvarez I, et al. Association between consumption of ultra-processed foods and all cause mortality: SUN prospective cohort study. BMJ 2019; 365: 11949 .

70 Srour B, Fezeu LK, Kesse-Guyot E, et al. Ultra-processed food intake and risk of cardiovascular disease: prospective cohort study (NutriNet-Santé). BMJ 2019; 365: 11451.

71 Feeley AB, Ndeye Coly A, Sy Gueye NY, et al. Promotion and consumption of commercially produced foods among children: situation analysis in an urban setting in Senegal. Matern Child Nutr 2016; 12 (suppl 2): 64-76.

72 Pries AM, Rehman AM, Filteau S, Sharma N, Upadhyay A, Ferguson EL. Unhealthy snack food and beverage consumption is associated with lower dietary adequacy and length-for-age z-scores among 12-23-month-olds in Kathmandu Valley, Nepal. J Nutr 2019; published online July 16. DOI:10.1093/jn/nxz140.

73 Reardon T, Barrett CB, Berdegué JA, Swinnen JFM. Agrifood industry transformation and small farmers in developing countries. World Dev 2009; 37: 1717-27.

74 Reardon TA, Berdegué JA, Farrington J. Supermarkets and farming in Latin America: pointing directions for elsewhere? Overseas Development Institute, 2002. https://www.odi.org/sites/odi.org.uk/ files/odi-assets/publications-opinion-files/1949.pdf (accessed Nov 7, 2019).

75 Hu D, Reardon T, Rozelle S, Timmer P, Wang H. The emergence of supermarkets with Chinese characteristics: challenges and opportunities for China's agricultural development. Dev Policy Rev 2004; 22: 557-86

76 Neven D, Odera MM, Reardon T, Wang H. Kenyan supermarkets emerging middle-class horticultural farmers, and employment impacts on the rural poor. World Dev 2009; 37: 1802-11. 
77 Euromonitor. Market sizes- historical- total volume- kilograms or litres per capita-packaged food, soft drinks, and hot drinks. [Statistics]. Euromonitor Passport International London, United Kingdom: Euromonitor; 2018

78 Bennett M. The world's food. Am J Agric Econ 1954; 36: 350-51.

79 Novta N, Wong J. Women at work in Latin America and the Caribbean. 2017. https://www.imf.org/en/Publications/WP/ Issues/2017/02/14/Women-at-Work-in-Latin-America-and-theCaribbean-44662 (accessed Nov 7, 2019).
80 Mincer J. Market prices, opportunity costs, and income effects. In: Christ CF, Friedman M, Goodman LA, et al, eds. Measurement in economics: studies in mathematical economics and econometrics in memory of Yehuda Grunfeld. Stanford: Stanford University Press, 1963: 67-82. 